\title{
Modelo para a mensuração do capital intelectual: uma abordagem fundamentada em recursos
}

\author{
Olivir Sebastião Malavskia,*, Edson Pinheiro de Lima ${ }^{\mathrm{b}}$, \\ Sérgio Eduardo Gouvêa da Costa ${ }^{c}$ \\ a,*olivirbr@yahoo.com.br, PUCPR, Brasil \\ be.pinheiro@pucpr.br, PUCPR, Brasil \\ ss.gouvea@pucpr.br, PUCPR, Brasil
}

\begin{abstract}
Resumo
A compreensão dos mecanismos de criação de valor na produção de bens ou serviços tem ocupado um lugar especial na agenda das empresas. 0 renascimento da Teoria Baseada em Recursos é um sinal da intensificação desta busca, em que se procura identificar o papel dos recursos, capacitações e competências na criação de valor nos sistemas de operações. Este trabalho desenvolve um modelo fundamentado no conceito de capital intelectual para articular recursos, capacitações e competências organizacionais. 0 modelo é construído a partir das definições das variáveis recursos, capacitações, competências e capital intelectual, trabalhando esses elementos em seus diferentes níveis de análise. A estrutura utilizada para a construção do modelo de integração fundamenta-se no modelo do navegador Skandia, apropriando-se das suas dimensões de desempenho para fins de desenvolvimento deste trabalho. 0 resultado é um modelo que explica a dinâmica de integração de recursos, capacitações e competências para a avaliação da criação de valor na forma de capital intelectual.
\end{abstract}

Palavras-chave

Teoria baseada em recursos. Capital intelectual. Competências organizacionais. Capacitações organizacionais. Sistemas de medição de desempenho.

\section{Introdução}

Para que se possa desenvolver uma melhor compreensão acerca da dinâmica da concorrência, deve-se ampliar o escopo da análise estratégica para além das definições de posicionamento competitivo. 0 posicionamento competitivo de uma empresa é fruto de uma trajetória desenvolvida ao longo do tempo, em que diferentes processos organizacionais e de gestão mobilizaram as competências da organização. Estas competências representam a habilidade de uma organização em coordenar a distribuição e mobilização de capacitações e recursos organizacionais (CHEN; WU, 2007; DREJER; RIIS, 2000; TEECE; PISANO; SHUEN, 1997; SANCHEZ; HEENE, 1997; DOZ, 1996).

Historicamente, os estudos dos problemas relacionados à dinâmica dos recursos de uma organização (recursos humanos, estruturais e infraestruturais) vêm sendo tratados no âmbito de conceitos originados na Teoria Baseada em
Recursos como: capacitações, competências e capital intelectual. Esses conceitos foram sendo desenvolvidos ao longo do tempo e têm como marco inicial o trabalho de Penrose (1959), que apresentou um modelo para a teoria da firma, em que a organização é definida como um conjunto de recursos produtivos. Trabalhos como os de Teece (1982), Rumelt (1984) e Wernerfelt (1984) atribuem aos recursos de uma organização um papel estratégico, enquanto que estudos como os de Grant (1991), Peteraf (1993) e Barney (1996) alocam a Teoria Baseada em Recursos no processo estratégico das organizações.

$\mathrm{Na}$ área de gestão de operações, os conceitos derivados da Teoria Baseada em Recursos têm contribuído para o desenvolvimento de um novo entendimento dos sistemas produtivos, especificamente em dois níveis principais: estratégia de produção e organização do trabalho. No primeiro 
nível, estratégia de produção, o uso da visão baseada em recursos está associado a conceitos como visão da manufatura (MASLEN; PLATTS, 2000), competências essenciais (PRAHALAD; HAMEL, 1990), competências organizacionais (MILLS; PLATTS; BOURNE, 2003a, b; LEWIS, 2003) e capacitações organizacionais (YUNG-CHING; TSUI-HSU, 2006; HAFEEZ; ZHANG; MALAK, 2002). No segundo nível, organização do trabalho, os modelos de organização e de gestão de pessoas fundamentam-se na gestão por competências (ZARIFIAN, 2001).

Nas ciências contábeis, particularmente nos processos de avaliação dos ativos de uma empresa, modelos e processos vêm sendo desenvolvidos para lidar com os aspectos intangíveis dos recursos, capacitações e competências das organizações. Tais desenvolvimentos estão orientados para a definição e mensuração do "capital intelectual" da empresa. Os trabalhos de Lev (2001), Stickney e Weil (2001), Dzinkowski (2000), Sveiby (1998), Stewart (1999), Edvinsson e Malone (1998) e Kaplan e Norton (1997), entre outros, apresentam a evolução deste conceito a partir da metade dos anos 90 .

Um dos grandes problemas verificados na avaliação dos ativos intangíveis é a falta de diferenciação contábil entre estes e os ativos tangíveis. Tal falta de diferenciação prejudica a compreensão das variáveis e processos responsáveis pela criação de valor para gestores, analistas, investidores e formuladores de políticas. Esse problema fez com que se constatasse que a classificação e mensuração dos ativos intangíveis, ou seja, a definição e mensuração do capital intelectual de uma organização, eram necessidades reais (SVEIBY, 1998; STEWART, 1998).

0 presente trabalho é um exercício de natureza teórica e situa-se na interface entre a mobilização de recursos e capacitações de uma organização e a mensuração do seu capital intelectual, isto é, define uma aplicação para a Teoria Baseada em Recursos nos modelos de mensuração do capital intelectual. 0 modelo proposto estabelece relações de composição entre a mobilização de recursos e as capacitações, na forma de competências organizacionais, e a criação de valor para a empresa, representado pelo seu capital intelectual. 0 "lugar" em que se desenvolvem essas relações é caracterizado por atividades que cooperam entre si nos diferentes processos organizacionais e de gestão. No processo de criação de valor destaca-se o papel de mediação desenvolvido pelas competências organizacionais. Ao final do artigo apresenta-se um exemplo de avaliação do capital intelectual em dois exercícios contábeis de uma empresa de serviços.

\section{Desenvolvimento do modelo: abordagem metodológica}

A ideia central do trabalho é associar, de forma mensurável, por intermédio de um modelo conceitual, os conceitos de recursos, capacitações e competências. Para tanto, busca-se na mensuração do capital intelectual, um modelo que explique a integração de tais conceitos, com vistas a explicar a criação de valor para a empresa. Tal explicação é construída utilizando a lógica de demonstrações contábeis.

Para fins de desenvolvimento do modelo de integração, utilizou-se o modelo de mensuração do capital intelectual desenvolvido pela Skandia, empresa de seguros sueca sediada em Estocolmo (EDVINSSON; MALONE, 1998).

0 desenvolvimento do presente trabalho fundamenta-se em pesquisa bibliográfica que identifica um conjunto de conceitos que são sistematizados e sintetizados no modelo teórico proposto. 0 desenvolvimento teórico apresentado permite criar um arcabouço teórico capaz de sustentar ou subsidiar as relações de composição entre as variáveis recursos, capacitações, competências e a sua aplicação na mensuração do capital intelectual (BERTO; NAKANO, 1998).

Para Apostel (1991), modelos tratam da simplificação, redução, concretização, experimentação, ação, extensão, globalização, explicação e formação de uma teoria. Dentro desta perspectiva, uma das funções principais é a explanatória e redutora de complexidade, no sentido de que permite que uma determinada classe de fenômenos possa ser visualizada e compreendida, o que de outra forma não seria possível devido à sua magnitude e complexidade.

Pode-se ainda vincular o trabalho realizado a um modelo de ciclo de vida de uma pesquisa voltada ao desenvolvimento de modelos para a mensuração do capital intelectual. De acordo com Neely (2005), o presente trabalho encontra-se no estágio de proposição de um modelo e do desenvolvimento de processos e procedimentos para a sua aplicação.

0 modelo proposto articula elementos de natureza estrutural, definindo variáveis e as suas relações, bem como explora a dinâmica dessas relações, tendo como objetivo central a mensuração do capital intelectual (FOLAN; BROWNE, 2005).

De acordo com Whetten (2003), um artigo conceitual deve ter a sua justificativa fundamentada na utilidade da reflexão desenvolvida. 0 presente trabalho trata aspectos estruturais e procedurais, inter-relacionando conceitos da Teoria Baseada em Recursos e modelos de mensuração do capital intelectual. Na medida em que se propõe a discutir 
a operacionalização dos conceitos relacionados a mensuração do capital intelectual, pode-se dizer que há uma sintonia com a produção científica no tema.

Dada a abordagem metodológica utilizada, é possivel apresentar as definições dos elementos que são trabalhados no modelo conceitual.

\section{Recursos, capacitações e competências}

A compreensão do papel estratégico que um recurso ou capacidade pode desempenhar na estratégia de uma empresa tem suas raízes na análise SWOT. Em geral, as forças e fraquezas de uma organização são resultado: das forças e fraquezas dos indivíduos que compõem a organização; da forma como essas capacitações individuais são integradas no trabalho coletivo; da qualidade da coordenação dos esforços das equipes na transformação dos recursos e capacitações em valor (GALBREATH, 2005; PETERAF, 1993; BARNEY, 1991; ANSOFF, 1990; ANDREWS, 1987).

Uma trajetória evolutiva da aplicação da Teoria Baseada em Recursos pode ser desenvolvida a partir do trabalho de Penrose (1959). Tem-se nos trabalhos de Nelson e Winter (1982) com a teoria evolucionária da firma e de Wernerfelt (1984) com a visão baseada em recursos um marco no desenvolvimento de modelos organizacionais baseados em recursos. A aplicação desses conceitos no desenvolvimento da estratégia empresarial é abordada no trabalho de Rumelt (1984), de Dierickz e Cool (1989), de Barney J. (1991), Barney J. B. (1996), de Peteraf (1993) e de Mintzberg, Ahlstrand e Lampel (2000). Atualmente, este tema está presente nos estudos acerca da estratégia de operações ou de produção, particularmente na definição da Visão da Manufatura ou Visão das Operações, conforme se pode encontrar em Maslen e Platts (2000), De Toni e Tonchia (2002), Johansen e Riis (2003) e Mills, Platts e Bourne (2003a, b).

Recursos, no escopo de desenvolvimento do presente trabalho, são definidos pelo seu potencial de gerar e dar forma a serviços. Geralmente, os recursos são considerados independentemente de seu uso ou aplicação, enquanto que os serviços vinculam-se a uma função ou atividade. É comum usar o termo "feixe" de recursos para vinculá-los a capacitações e serviços (PENROSE, 1959).

Como os recursos não se vinculam diretamente a um uso específico, é comum valer-se de uma tipologia ou classificação para definir a sua natureza e as suas propriedades. São classificados em recursos tangíveis e recursos intangíveis. Operacionalmente, podem ser recursos tangíveis: recursos humanos; recursos de infraestrutura física na forma de tecnologias de processo e de produto; recursos materiais; recursos informacionais; recursos financeiros. Os recursos intangíveis podem ser encontrados: no âmbito da cultura organizacional; na forma de rotinas organizacionais; know-how dos colaboradores da empresa; nas definições de marca e de imagem de uma empresa. Os recursos por si só não produzem valor, há necessidade de selecioná-los, combiná-los e mobilizá-los via serviços em atividades e processos.

Entende-se por capacitação a integração de um conjunto de recursos que é específico a uma organização, considerada no seu todo ou em suas partes. As capacitações manifestam-se via serviços nos processos organizacionais e de gestão, mobilizando combinações tipicamente complexas de recursos tangíveis e intangíveis. As capacitações organizacionais definem o nível de apropriação dos recursos por parte dos processos e sistemas organizacionais. São, portanto, uma combinação específica de recursos da firma integrados aos sistemas organizacionais e de dificil transferência para outra firma (STEWART, 1998; AMIT; SHOEMAKER, 1993; STALK; EVANS; SHULMAN, 1992).

$\mathrm{Na}$ perspectiva da visão baseada em recursos e na abordagem adotada neste trabalho os recursos e as capacitações são tratados essencialmente como variáveis de estoque. É evidente que para recursos esta afirmação é clara, no entanto, para as capacitações há que se estabelecer uma trajetória em que, ao longo da experiência de mobilizar recursos para determinados serviços, acumula-se um histórico de combinações de recursos que formam um conjunto de capacitações especificamente derivado das situações vividas pela empresa. $\mathrm{Na}$ abordagem das capacitações dinâmicas, mais importante que o estoque atual de recursos é a capacidade de acumular e combinar novos recursos em novas configurações capazes de gerar fontes adicionais de renda (VASCONCELOS; CYRINO, 2000; TEECE; PISANO; SHUEN, 1997).

Christensen e Overdorf (2000) destacam a necessidade de a gerência da empresa pensar as capacitações de sua organização tão cuidadosamente como o fazem com os seus quadros técnicos e gerenciais. Para tal, sugerem a análise de uma capacitação ao longo de três dimensões: considerando não só os recursos tangiveis e intangiveis de que a firma dispõe, e os processos que os operam, como os processos de interação, coordenação, comunicação e tomada de decisão desenvolvidos pela equipe que transforma os insumos em resultados, e não deixando de observar também os valores culturais pelos quais os empregados definem suas prioridades e estabelecem as relevâncias relativas no âmbito de 
seu trabalho cotidiano. As capacitações constituem elementos de mediação entre processos e recursos. Particularmente, os processos citados são responsáveis pela seleção, coordenação e integração dos recursos, capacitações e competências a outros processos organizacionais ou de gestão.

As capacitações também poderiam ser definidas como prática de um dado processo, na medida em que endereçam os recursos a finalidades específicas, fundamentando o conceito de "rotina" da economia "evolucionária" de Nelson e Winter (1982).

Pode-se também traçar uma síntese evolutiva do conceito de capacitações tendo como referência os trabalhos de Cohen e Levintahl (1990), Stalk, Evans e Shulman (1992) e Amit e Shoemaker (1993). 0 conceito evoluiu na medida da sua aplicação e síntese, conforme descrito nos trabalhos de Teece et al. (1997), Mintzberg, Ahlstrand e Lampel (2000), Montealegre (2001) e Hafeez, K., Zhang, Y. e Malak (2002).

Os recursos e capacitações de uma organização definem o "potencial" de uma organização gerar valor. A mobilização dos recursos e capacitações nos processos e atividades organizacionais define as competências das organizações, explicando a criação de valor.

A ação de mobilizar, coordenar, combinar e integrar recursos e capacitações deu origem ao conceito de competência. Os trabalhos de Hamel e Prahalad (1989) e Prahalad e Hamel (1990) estabelecem um marco na discussão do uso estratégico das competências organizacionais. Este aspecto dinâmico e evolucionário é que diferencia uma capacitação organizacional de uma competência organizacional, isto é, capacitações são formadas, enquanto competências são desenvolvidas. São exemplos deste esforço para estabelecer um marco conceitual e desenvolver modelos de aplicação, na literatura, os trabalhos de Sanchez e Heene (1997), Zarifian (2001), Fleury e Oliveira Jr. (2001), Fleury, A. e Fleury, M. T. L. (2003), Lewis (2003), Mills, Platts e Bourne (2003a) e Pinheiro de Lima e Lezana (2005).

Sanchez e Heene (1997) desenvolvem um modelo de construção de competências. Em tal modelo, as competências têm características multidimensionais, sendo descritas como competências dinâmicas, competências sistêmicas, competências cognitivas e competências holísticas.

Sanchez e Heene (1997) e Pinheiro de Lima e Lezana (2005) definem competência organizacional como a "habilidade" de coordenar a distribuição dos recursos e capacitações da organização em uma direção estabelecida para atingir os objetivos determinados, sendo esta a abordagem adotada neste trabalho. Esta definição é estabelecida tendo como base o fato de que as capacitações organizacionais contribuem para a formação de padrões de ação ou de rotinas organizacionais na medida em que identificam e endereçam os recursos organizacionais a determinadas finalidades e usos. As competências são resultado de um processo de aprendizagem contínuo e dependem fundamentalmente da mobilização de recursos e capacitações.

As combinações de valor agregado, de recursos e capacitações seriam, na realidade, as competências organizacionais. À competência organizacional também podem ser incorporados os atributos da experiência, do sistema de valores e da rede social de relacionamentos, na medida em que se trabalha o aspecto cumulativo desses atributos, e, portanto, estabelece-se uma trajetória cumulativa de aprendizagem. Existem princípios, ou pressupostos, coletivos que servem de base para qualquer processo de interpretação e desenvolvimento, os quais se associam aos processos de negócios e podem extrapolar as fronteiras organizacionais. Desta forma, contribuem para a definição das competências organizacionais: o conceito de habilidade, intrínseco à definição de competência; a direção estabelecida na realização da estratégia, representando as necessidades organizacionais; as capacitações, identificando a base de conhecimento organizacional e integrando-a aos processos, sistemas e produtos; e o sistema de valores, fundamentando e regulando a formação das competências.

Os conceitos de recurso, capacitação e competência podem ser trabalhados na forma de relações de agrupamento, isto é, capacitações agrupam recursos, enquanto que competências mobilizam capacitações e recursos. Tais elementos podem vincular-se aos modelos de mensuração do capital intelectual na medida em que as suas dinâmicas de integração ao processo de criação de valor são estudadas.

Os recursos, capacitações e competências "endereçados" às operações de uma empresa constituem o seu capital intelectual, na medida do seu potencial para criar valor em suas atividades e processos organizacionais e de gestão. Estudos acerca do capital intelectual procuram quantificar e qualificar este processo de apropriação desenvolvido pelas organizações.

\section{Mensuração do capital intelectual}

Na medida da sua intangibilidade, os recursos, capacitações e competências organizacionais constituem o capital intelectual da empresa. Eles podem ser mensurados na perspectiva do capital humano, do capital relacional e do capital 
estrutural. 0 processo de acumulação se dá pela aquisição dos recursos ou pela sua identificação. No caso das capacitações e competências, estas constituem construções de segunda ordem, ou seja, a sua formação se dá ao longo do tempo, fruto da utilização dos recursos. É na atividade que os recursos são articulados e mobilizados, via serviços. De forma geral, os processos organizacionais e de gestão são os responsáveis pela mobilização de recursos, formando capacitações e desenvolvendo competências.

Segundo Pfeil (2003), no início das pesquisas acerca dos recursos intangíveis, o capital intelectual era definido como sendo a diferença entre o valor de mercado e o valor contábil das ações de uma empresa, definição esta conhecida também como goodwill. Para o IAS (INTERNATIONAL..., 2006), goodwill é reconhecido como um todo, sendo o somatório de todos os fatores intangíveis.

A pesquisa acerca do capital intelectual pode ter seu marco inicial associado ao trabalho de Hiroyuki (1980), na medida em que se discute a mobilização dos chamados ativos ocultos em empresas do Japão. Conceitos e modelos são criados, conforme evidenciado nas obras de Crawford (1994), Stewart (1999), Sveiby (1998) e Edvinsson e Malone (1998). Dos conceitos e modelos para mensuração do capital intelectual, seguem estudos de aplicação na forma de relatórios e sistemas de avaliação, como podemos encontrar nos trabalhos de Dzinkowski (2000), Lev (2001), Wernke (2002), Anne Wu (2005) e Whitwell, Lukas e Hill (2007).

Para a SMAC (SOCIETY..., 2006), os ativos intelectuais são aqueles itens baseados em conhecimento, os quais a companhia possui e que the produzirão um fluxo futuro de benefícios, consequentemente para os seus acionistas, e isto pode incluir processos tecnológicos, modelos de gestão e consultoria, estendendo-se também à propriedade intelectual. Segundo Dzinkowski (2000), definições de ativos intelectuais são tipicamente menos concretas e se aplicam a um âmbito potencialmente mais amplo do que o daqueles ativos intangíveis capturados sob o guarda-chuva da propriedade intelectual. Para que se possa delimitar o escopo de definição dos ativos intangíveis, a Figura 1 apresenta um conjunto de categorias.

0 Quadro 1 apresenta um conjunto de exemplos associados aos ativos tangíveis e intangíveis. Tais exemplos podem contribuir para uma definição operacional dos ativos intangíveis, estabelecendo um conjunto de tipos.

Lynn (2000) desenvolve um constructo de três componentes para conceituar o capital intelectual: o capital humano, o capital relacional, e o capital estrutural (ou organizacional). 0 capital humano é representado pelo know-how, capacitações, habilidades e especializações técnicas dos recursos humanos de uma organização.

Para Terra e Fraga (2006), o capital relacional é definido como a soma de todos os recursos associados às relações externas da empresa: consumidores, fornecedores, parceiros e investidores.

0 capital estrutural é definido como o conhecimento apropriado pela empresa. Ele engloba processos organizacionais, softwares, procedimentos, sistemas, cultura, banco de dados etc. Para Terra e

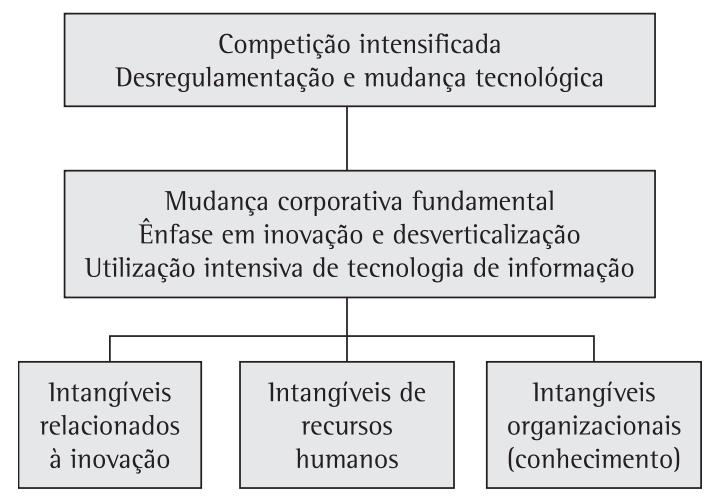

Figura 1. Estruturação das categorias de intangíveis. Fonte: Lev (2001).

Quadro 1. Tipos de ativos de uma empresa.

\begin{tabular}{|l|l|l|}
\hline \multicolumn{1}{|c|}{ Ativos tangíveis } & \multicolumn{2}{c|}{ Ativos intangíveis } \\
\hline - Ativo fixo & - Direitos de propriedade intelectual (DPI) & - Goodwill \\
- Trabalho em andamento & - Direitos autorais & - Relacionamentos internos e externos \\
- Recursos naturais & - Patentes & - Força de trabalho \\
- Matérias-primas & - Banco de dados & - Clientes \\
- Estoques & - Know-how & - Fornecedores \\
- Capital financeiro & - Ticenças & - Tecnologia \\
- Debêntures & - Segredos de fabricação & - Competência humana \\
- Ações & - Marcas registradas & - Habilidades \\
& - Softwares & \\
\hline
\end{tabular}

Fonte: Granstrand (1999). 
Fraga (2006), o capital estrutural pode ser divido em duas subclassificações: propriedade intelectual e ativos de infraestrutura. Lynn (2000) estabelece que o capital estrutural é a espinha dorsal da própria empresa, que envolve sua capacitação organizacional e inclui seu planejamento administrativo e sistemas de controle, processos, redes funcionais, políticas e até mesmo sua cultura, ou seja, tudo o que auxilia uma empresa a gerar valor.

A partir do Quadro 2 é possível verificar os tipos de capital intelectual existentes dentro de cada categoria e identificar uma forma de classificação.

Definido o "conteúdo" do capital intelectual, é possível tratar de alguns aspectos relativos a sua mensuração. Dzinkowski (2000) identifica que a necessidade de fazer comparações entre o valor do capital intelectual de diferentes empresas levou ao desenvolvimento de três indicadores amplos, utilizados em demonstrações financeiras auditadas: a diferença entre o valor contábil e valor de mercado das ações (market-books values); o "q" de Tobin representando a proporção entre o valor de mercado da empresa e o custo de reposição de seus ativos; e o valor intangivel calculado (intangible value calculate ou IVC).

0 modelo escolhido para operacionalizar a medida do capital intelectual é o do navegador Skandia, considerado modelo de referência na literatura de capital intelectual. 0 modelo produz um relatório de avaliação do capital intelectual cujas medidas são organizadas segundo cinco dimensões: financeira, do cliente, dos processos, da renovação e desenvolvimento e humana, conforme representado na Figura 2. Ao todo, são aproximadamente cem indicadores (EDVINSSON; MALONE, 1998).
0 fluxo financeiro gerado por uma organização constitui, em última instância, a medida mais tangivel de seu valor. Ele é também a fonte de sua retribuição em termos de lucros, salários, rendimentos e dividendos. 0 Quadro 3 apresenta os indicadores da dimensão financeira do navegador Skandia.

Para a seleção dos indicadores do Quadro 4, foram considerados cinco aspectos relacionados ao cliente: tipo de cliente, duração do relacionamento com o cliente, sucesso do cliente, papel do cliente e suporte ao cliente.

0 sistema de avaliação para os processos, representado no Quadro 5, calcula índices que se enquadram em quatro critérios e estão relacionados à infraestrutura de tecnologia: atribui valor monetário à tecnologia de processo somente quando esta contribui para o valor da empresa; acompanha a idade e o atual suporte oferecido pelo fornecedor à tecnologia de processo; avalia não só

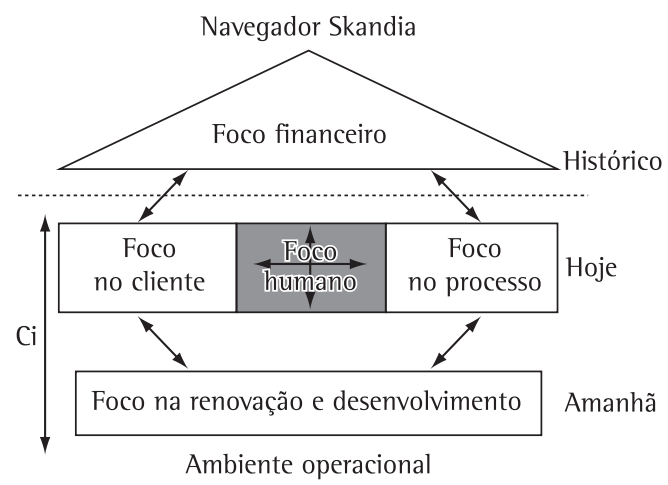

Figura 2. Navegador Skandia. Fonte: Edvinsson e Malone (1998).

Quadro 2. Elementos do capital intelectual.

\begin{tabular}{|c|c|}
\hline Capital humano & Capital relacional \\
\hline $\begin{array}{l}\text { - Know-how } \\
\text { - Educação } \\
\text { - Qualificação vocacional } \\
\text { - Conhecimento relacionado ao trabalho } \\
\text { - Avaliações ocupacionais } \\
\text { - Avaliações psicométricas } \\
\text { - Competências relacionadas ao trabalho } \\
\text { - Impeto de empreendedorismo, inovatividade, capacitações } \\
\text { proativas e reativas, mutabilidade } \\
\end{array}$ & $\begin{array}{l}\text { - Acordos de franquias } \\
\text { - Clientes } \\
\text { - Fidelidade do cliente } \\
\text { - Nomes de companhias } \\
\text { - Pedidos em carteira } \\
\text { - Canais de distribuição } \\
\text { - Colaborações comerciais } \\
\text { - Acordos de licenciamento } \\
\text { - Contratos favoráveis }\end{array}$ \\
\hline \multicolumn{2}{|c|}{ Capital estrutural } \\
\hline Propriedade intelectual & Ativos de infraestrutura \\
\hline $\begin{array}{l}\text { - Patentes } \\
\text { - Direitos autorais } \\
\text { - Direitos de projeto } \\
\text { - Segredos industriais } \\
\text { - Marcas registradas }\end{array}$ & $\begin{array}{l}\text { - Filosofia gerencial } \\
\text { - Cultura corporativa } \\
\text { - Processos gerenciais } \\
\text { - Sistemas de informação } \\
\text { - Sistema de rede }\end{array}$ \\
\hline
\end{tabular}

Fonte: Pacheco (2005). 
Quadro 3. Indicadores da dimensão financeira.

\begin{tabular}{l} 
Indicadores financeiros \\
\hline - Ativos representados pelos fundos \\
- Ativos representados pelos fundos/empregado \\
- Receita/empregado \\
- Receita/ativos administrados \\
- Receita de prêmios de seguro \\
- Receita de prêmios de seguros resultantes de uma nova \\
- operação \\
- Tempoturamento/empregado dedicado aos clientes/número de horas \\
- trabalhadas pelos empregados \\
- Resultado dos seguros/empregado \\
- Índices de perdas em comparação à média do mercado \\
- Rendimento direto \\
- Receita operacional líquida \\
- Valor de mercado \\
- Valor de mercado/empregado \\
- Retorno sobre o valor do ativo líquido \\
- Retorno sobre o ativo líquido resultante da atuação em \\
- novos negócios \\
- Despesas com Tl/despesas administrativas \\
- Valor agregado/número de empregados em Tl \\
- Investimentos em Tl \\
Fonte: Edvinsson e Malone (1998).
\end{tabular}

Fonte: Edvinsson e Malone (1998).

Quadro 4. Indicadores da dimensão cliente.

\begin{tabular}{|l|}
\multicolumn{1}{|c|}{ Indicadores de cliente } \\
\hline - Participação no mercado \\
- Número de clientes \\
- Número de clientes perdidos \\
- Acesso por telefone \\
- Apólices de seguro sem resgate \\
- Classificação dos clientes \\
- Número de visitas dos clientes à empresa \\
- Número de dias empregados em visitar clientes \\
- Cobertura de mercado \\
- Índice de ociosidade \\
- Rendimento bruto de aluguéis/empregado \\
- Número de contratos \\
- Economia de gastos/contrato \\
- Número de pontos de venda \\
- Número de administradores de fundos \\
- Número de clientes internos de Tl \\
- Número de clientes externos de Tl \\
- Número de contratos/empregado da área de Tl \\
- Conhecimento de Tl por parte dos clientes
\end{tabular}

Fonte: Edvinsson e Malone (1998).

as especificações do desempenho do processo, mas também a real contribuição para a produtividade da empresa; incorpora um índice de desempenho de processo para as metas padronizadas deste desempenho.
Quadro 5. Indicadores da dimensão processos.

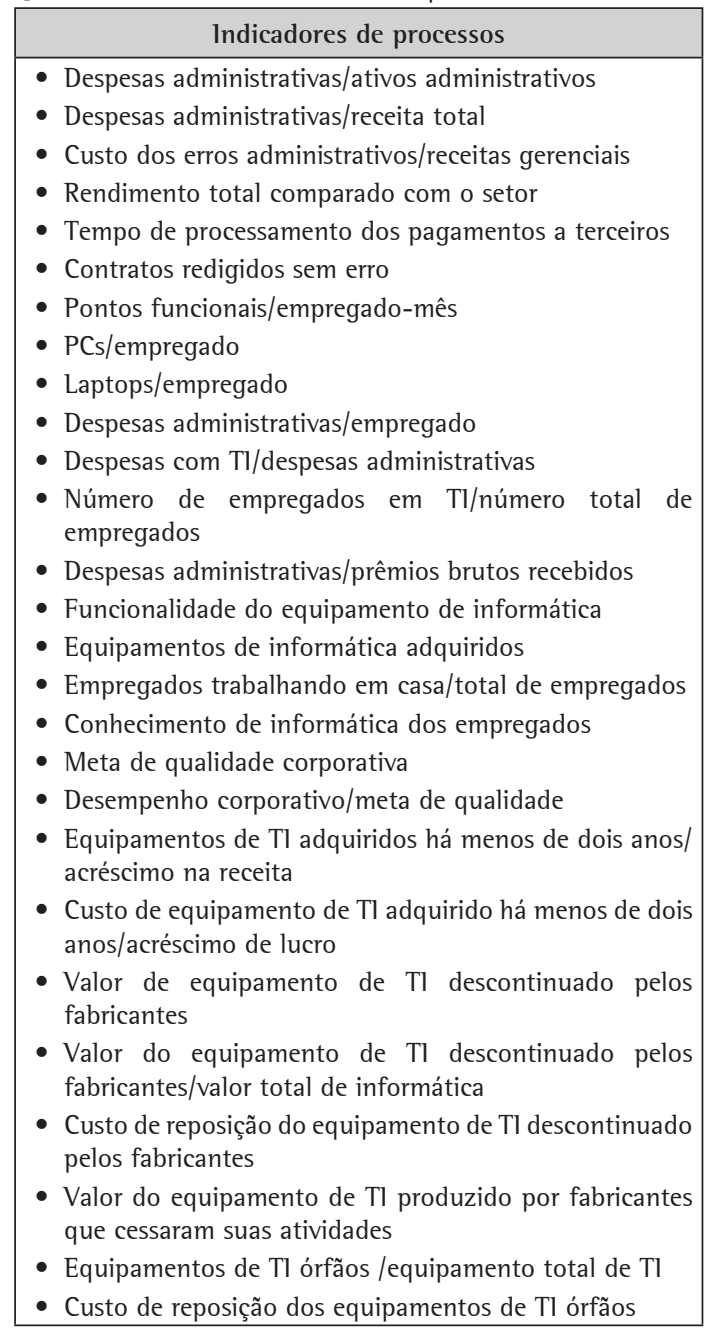

Fonte: Edvinsson e Malone (1998).

A dimensão renovação e desenvolvimento procura visualizar as oportunidades que irão definir o futuro da organização. Os seus indicadores estão diametralmente opostos aos demonstrativos financeiros. Enquanto estes fixam em caráter definitivo o desempenho da organização que acaba de ocorrer, a renovação e desenvolvimento tenta projetar o futuro imediato, estabelecendo o que a empresa está realizando no presente a fim de preparar-se adequadamente para aproveitar oportunidades futuras. 0 Quadro 6 apresenta o conjunto de indicadores para a renovação e desenvolvimento.

A dimensão humana do navegador Skandia, apresentada no Quadro 7, é a mais dinâmica do navegador elaborado pela Skandia. É também a dimensão mais crítica do modelo de mensuração do capital intelectual, por apoiar-se na avaliação, às vezes subjetiva, de gerentes e colaboradores. 
Além dos indicadores que compõem as cinco dimensões, o modelo ainda permite a síntese em um macroindicador que é definido pela Equação 1 (EDVINSSON; MALONE, 1998):

Capital intelectual organizacional $=i . C$

onde:

- $i$ = coeficiente de eficiência da utilização do capital intelectual;

- $C=$ valor monetário do capital intelectual.

Quadro 6. Indicadores da dimensão renovação e desenvolvimento.

Indicadores de renovação e desenvolvimento

- Despesas com o desenvolvimento de competências/ empregado

- Índice de satisfação do empregado

- Despesas de marketing/cliente

- Despesas de marketing/ativos administrados

- Porcentagem das horas de "Método e Tecnologia"

- Porcentagem das horas de treinamento

- Porcentagem das horas de desenvolvimento

- Despesas com R\&D/despesas administrativas

- Despesas com Tl/despesas administrativas

- Despesas de treinamento/empregado

- Despesas de treinamento/despesas administrativas

- Prêmios de novos tipos de seguro

- Crescimento do prêmio líquido

- Despesas de desenvolvimento de negócios/despesas administrativas

- Porcentagem de empregados com menos de 40 anos

- Despesas de desenvolvimento de tecnologia da informação/despesas de Tl

- Despesas de treinamento em Tl/despesas de $\mathrm{Tl}$

- Recursos investidos em R\&D/investimento total

Fonte: Edvinsson e Malone (1998).

Quadro 7. Dimensão humana.

\begin{tabular}{|c|}
\hline \\
\hline $\begin{array}{l}\text { - Índice de liderança } \\
\text { - Índice de motivação } \\
\text { - Índice de empowerment } \\
\text { - Número de empregados } \\
\text { - Número de empregados/número de empregados em } \\
\text { parcerias } \\
\text { - Rotatividade dos empregados } \\
\text { - Número médio de anos de serviços com a empresa } \\
\text { - Número de gerentes } \\
\text { - Número de gerentes do sexo feminino } \\
\text { - Despesas de treinamento/empregado } \\
\text { - ldade média dos empregados } \\
\text { - Porcentagem de empregados com menos de } 40 \text { anos } \\
\text { - Tempo de treinamento (dias/anos) }\end{array}$ \\
\hline
\end{tabular}

Fonte: Edvinsson e Malone (1998).
0 valor de C é obtido de uma relação que contém os indicadores mais representativos de cada área das cinco dimensões, avaliados monetariamente, excluindo os que pertencem mais propriamente ao balanço patrimonial. Esses indicadores referem-se ao exercício social. 0 Quadro 8 apresenta um conjunto de referência que pode compor a estrutura de mensuração do capital intelectual de uma organização.

0 Quadro 9 apresenta elementos para definição do valor compensatório que é o coeficiente de eficiência $i$ da fórmula do capital intelectual organizacional. Do mesmo modo que a variável C, este coeficiente é obtido a partir da agregação de indicadores selecionados e representativos de cada uma das cinco dimensões do navegador Skandia. 0 coeficiente $i$ focaliza o desempenho atual quanto a medidas de sucesso ou fracasso.

Este conjunto de nove indicadores deve ser combinado em uma única medida da eficiência com

Quadro 8. Modelo de mensuração de capital intelectual.

\section{Capital intelectual}

1. Receitas resultantes da atuação em novos negócios (novos programas/serviços)

2. Investimento no desenvolvimento de novos mercados

3. Investimento no desenvolvimento do setor industrial

4. Investimento no setor de novos canais

5. Investimento em $\mathrm{Tl}$ aplicada a vendas, serviços e suporte

6. Investimento em $\mathrm{Tl}$ aplicada à administração

7. Novos equipamentos de $\mathrm{Tl}$

8. Investimento no suporte aos clientes

9. Investimento no serviço aos clientes

10. Investimento no treinamento de clientes

11. Despesas com clientes não relacionadas aos produtos

12. Investimento no desenvolvimento da competência de empregados

13. Investimento em suporte e treinamento relativo a novos produtos para os empregados

14. Treinamento especialmente direcionado aos empregados que não trabalham nas instalações da empresa

15. Investimento em treinamento, comunicação e suportes direcionados aos empregados permanentes de período integral

16. Programas de treinamento e suporte especialmente direcionados aos empregados temporários de período integral

17. Programas de treinamento e suporte especialmente direcionados aos empregados temporários de período parcial

18. Investimento no desenvolvimento de parcerias/joint ventures

19. Upgrades do EDI ou da rede eletrônica de dados

20. Investimento na identificação da marca (logotipo/nome)

Fonte: Edvinsson e Malone (1998). 
Quadro 9. Coeficiente de eficiência do capital intelectual.

\begin{tabular}{|l|}
\hline \multicolumn{1}{|c|}{ Eficiência do capital intelectual } \\
\hline 1. Participação no mercado (\%) \\
2. Índice de satisfação dos clientes (\%) \\
3. Índice de liderança (\%) \\
4. Índice de motivação (\%) \\
5. Índice de investimento em Pesquisa \& Desenvolvimento/ \\
$\quad$ investimento total (\%) \\
6. Índice de horas de treinamento (\%) \\
7. Desempenho/meta de qualidade (\%) \\
8. Retenção dos empregados (\%) \\
9. Eficiência administrativa/receitas (o inverso de erros \\
administrativos/receitas) (\%)
\end{tabular}

Fonte: Edvinsson e Malone (1998).

que a organização utiliza o seu capital intelectual. Pode-se trabalhar com médias aritméticas ou ponderadas.

Devido à diversidade das organizações, recomenda-se uma seleção criteriosa dos indicadores. 0 modelo de referência apresentado deve ser adaptado à realidade das empresas.

Definidos os conceitos recursos, capacitações, competências e capital intelectual, um modelo de integração que servirá de base para se desenvolver um exercício teórico acerca da dinâmica da criação de valor em uma organização pode ser trabalhado.

\section{Modelo para mensuração do capital intelectual}

Tendo como referência o arcabouço conceitual apresentado, em que se destaca o papel de conceitos como competências e capacitações organizacionais, na visão baseada em recursos, pode-se desenvolver uma proposta de modelo para mensuração do capital intelectual.

Sendo assim, por meio das capacitações organizacionais, intrínsecas às definições de processos e atividades organizacionais, na medida em que mediam a mobilização das capacitações individuais, das rotinas e práticas organizacionais e dos recursos (tangíveis e intangíveis), gera-se um portifólio de competências organizacionais (dinâmicas, sistêmicas e cognitivas).

0 modelo proposto fundamenta-se na analogia à estrutura de dois relatórios contábeis: o balanço patrimonial e a demonstração de resultado - DR. 0 balanço patrimonial é a demonstração contábil que evidencia qualitativa e quantitativamente, numa determinada data, a posição patrimonial e financeira da organização. Sua estrutura é formada por três grandes grupos: pelo ativo, pelo passivo e pelo patrimônio líquido - PL.
A demonstração de resultado é a demonstração contábil que evidencia a composição do resultado obtido num determinado período de operações da organização. A demonstração de resultado, observado o princípio de competência, evidenciará a formação de vários níveis de resultados mediante o confronto entre as receitas e os correspondentes custos e despesas, encerrando-se com o lucro ou prejuízo líquido da organização.

Tal como o patrimônio líquido de uma organização, na forma de seu capital social, as competências organizacionais são consideradas um fator básico para o início de qualquer empreendimento. Sendo assim, os processos de aquisição, construção e desenvolvimento de competências organizacionais equivalem à realimentação do patrimônio líquido por meio do seu resultado líquido, sendo este consequência da operacionalização da lógica contábil entre ativos e passivos. A competência constitui uma saída oriunda da mobilização de capacitações e recursos.

Partindo deste raciocínio, a fim de encerrar o ciclo funcional da lógica das demonstrações contábeis, é necessária a operacionalização destas competências, assim, as capacitações e recursos passam a representar os ativos da organização, os quais devem ser equilibrados pelo passivo, neste ensaio representado pelas perdas ou falhas na integração entre capacitações e recursos. $\mathrm{Na}$ equação fundamental da contabilidade, o total de ativos deve se igualar ao passivo mais o patrimônio líquido, ou seja, o conjunto resultante de competências organizacionais representa uma parte das capacitações e recursos. Desta forma, justifica-se o passivo como uma espécie de ausência ou de falha na mobilização de recursos e de capacitações.

Todavia, a conclusão do processo funcional das demonstrações contábeis se dá através da demonstração de resultado, ou seja, através da apuração do resultado líquido. Este resultado, na analogia desenvolvida, representa a integração entre as competências, capacitações e recursos da organização. 0 resultado desta integração fundamenta o desempenho atual da organização, bem como contribui para a formação de novas competências organizacionais. A demonstração de resultados é estruturada tendo como referência a Figura 3.

Desenvolvida a racionalidade estrutural do modelo, podem-se apresentar os elementos que compõem o processo de mensuração do capital intelectual, desenvolvendo-se uma lógica de processo que representará a dinâmica do 


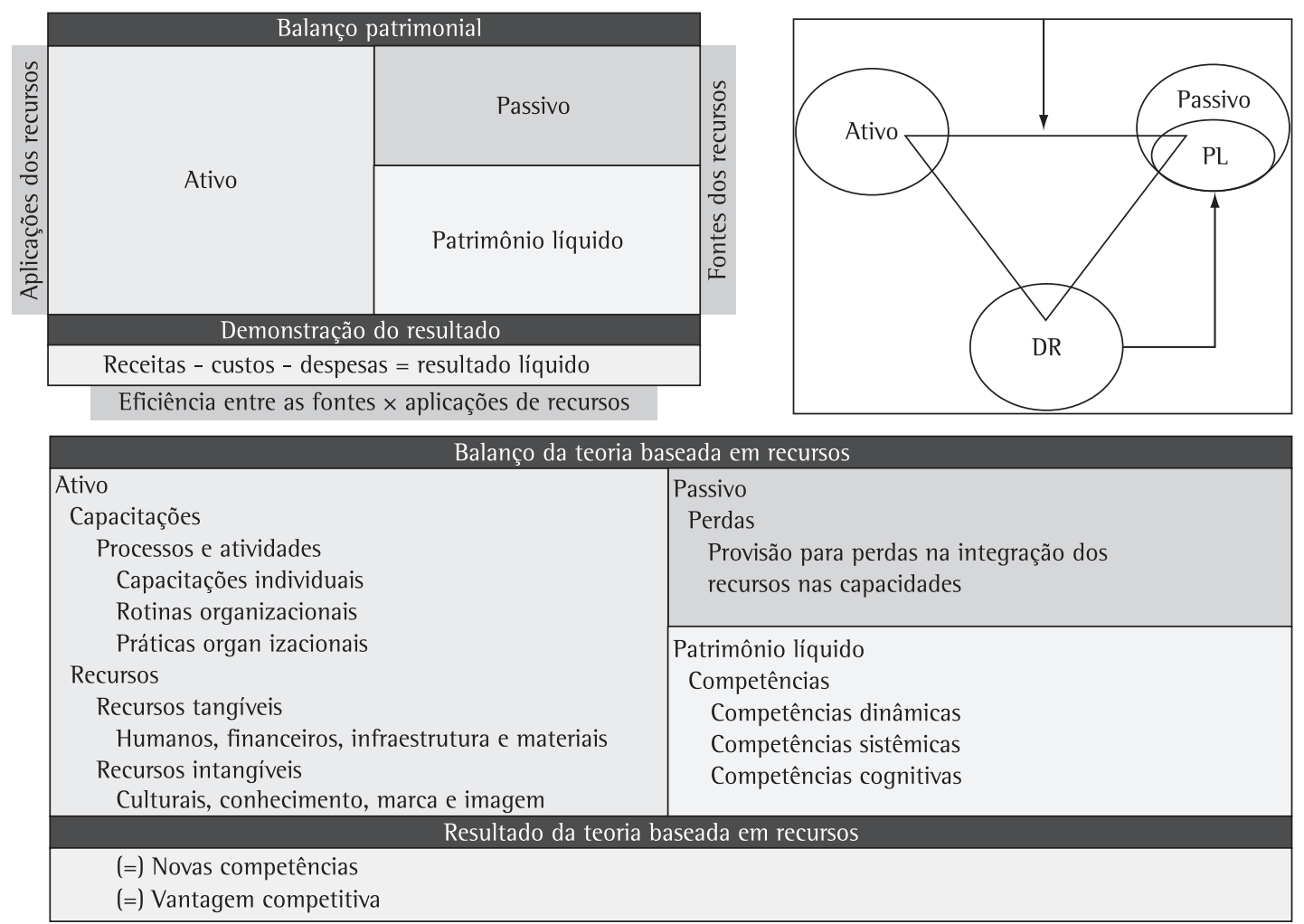

Figura 3. Lógica das demonstrações contábeis. Fonte: autores.

modelo proposto. Para tanto, é necessário que se identifiquem os elementos que definem a entrada do processo de mensuração.

Trabalhando o modelo de capital intelectual, representado pelo modelo do navegador Skandia, conceitos como tags de atributos determinam as referências do processo de mensuração para o navegador Skandia. A Figura 4 apresenta uma proposta de articulação entre os indicadores que compõem o modelo do navegador Skandia e a demonstração de resultados fundamentada na Teoria Baseada em Recursos.

Complementando os conceitos desenvolvidos para o capital intelectual, faz-se necessário nesta etapa uma breve apresentação das definições de tags de atributos. Delimitando o escopo de definição às áreas de Tecnologia da Informação e da Gestão do Conhecimento, tag pode ser considerada uma palavra-chave ou termo associado ou identificado com uma parte da informação (como um quadro, um artigo, um videoclipe, um conceito etc.) descreve-se assim o item e habilita-se a classificação de uma palavra-chave da informação aplicada. Como exemplo, a estrutura de navegação de páginas web em diferentes hipertextos é vinculada a tags ou palavras-chave. Tag corresponde a uma designação

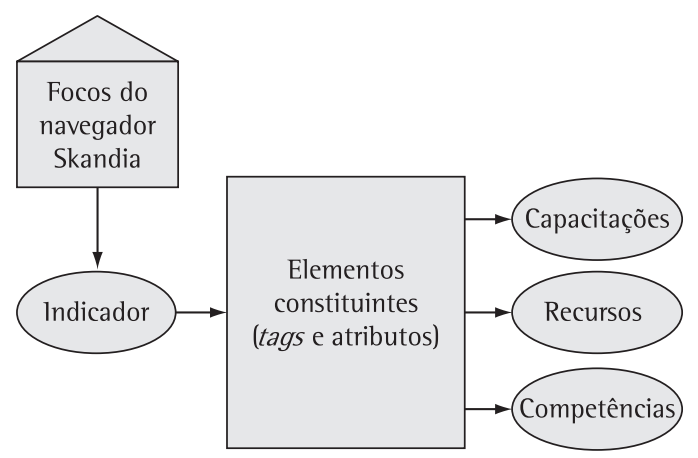

Figura 4. Integração entre o navegador Skandia e a demonstração de resultados. Fonte: autores.

do atributo, podendo-se estabelecer o paralelo com o nome de um campo de uma tabela de dados. Todos os atributos com a mesma designação devem corresponder ao mesmo tipo de dados, ou seja, irão registrar dados do mesmo campo (HEIJST; SPEK; KRUIZINGA, 1998).

É possível identificar um grupo básico de sete tags de atributos para o desenvolvimento do modelo de integração, tendo como referência a plataforma para gestão do conhecimento desenvolvida por Tiwana (2002). Os atributos 
utilizados são delimitados pela Teoria Baseada em Recursos e representam:

- Atividades: o atributo atividades compreende o "conteúdo" dos elementos existentes em cada um dos agrupamentos, ou seja, na forma de capital intelectual, competências organizacionais, capacitações organizacionais e recursos organizacionais. Este atributo está definido em tags não exclusivas, definição baseada na estrutura dos processos organizacionais e gerenciais proposta por Garvin (1998). As atividades do agrupamento capital intelectual estão representadas pelos focos ou dimensões do navegador Skandia. As definições das atividades que compõem os demais agrupamentos, competências, capacitações e recursos estão fundamentadas nas suas definições conceituais. A definição de atividade aqui utilizada fundamenta-se nos elementos que a constituem a não na dinâmica da relação entre eles;

- Domínio: é o atributo primário que guia o processo de meta search no modelo de integração. 0 atributo domínio será representado de acordo com as atividades de cada agrupamento. Suas tags são identificadas por verbos de ação ou por sua base de execução, que determinam junto com o atributo de forma as características fundamentais das relações com as tags de atividades. Define o "escopo" da dinâmica das relações no agrupamento; e
- Forma: o atributo de forma é definido pela representação física de determinado agrupamento. A definição deste atributo é complexa, no entanto, há como representá-lo através da dualidade de suas propriedades como: formal versus informal; individual versus coletivo; explícito versus tácito. Essencialmente, o que se está estudando é a "forma" de se integrar as tags de atividades e de domínio. Esta integração é a base fundamental do modelo, em que se inter-relacionam capital intelectual, competências, capacitações e recursos.

Aplicando as definições de tags ao modelo de integração da Figura 4, desenvolve-se a estrutura e as classificações das tags/atributos do primeiro agrupamento: o do capital intelectual, conforme apresentado no Quadro 10.

Quadro 10. Tags e atributos do capital intelectual.

\begin{tabular}{|c|c|c|}
\hline Atividades & Domínio & Forma \\
\hline $\begin{array}{l}\text { - Foco financeiro } \\
\text { - Foco no cliente } \\
\text { - Foco no processo } \\
\text { - Foco na renovação } \\
\text { e desenvolvimento } \\
\text { - Foco humano }\end{array}$ & $\begin{array}{l}\text { - Fonte de recursos } \\
\text { - Produtos e serviços } \\
\text { - Fluxos de atividades } \\
\text { - Produtos e serviços } \\
\text { - Fonte de recursos }\end{array}$ & $\begin{array}{l}\text { - Tangível } \\
\text { - Resultados } \\
\text { - Operações } \\
\text { - Aplicação dos } \\
\text { investimentos } \\
\text { - Intangível }\end{array}$ \\
\hline
\end{tabular}

Fonte: autores.

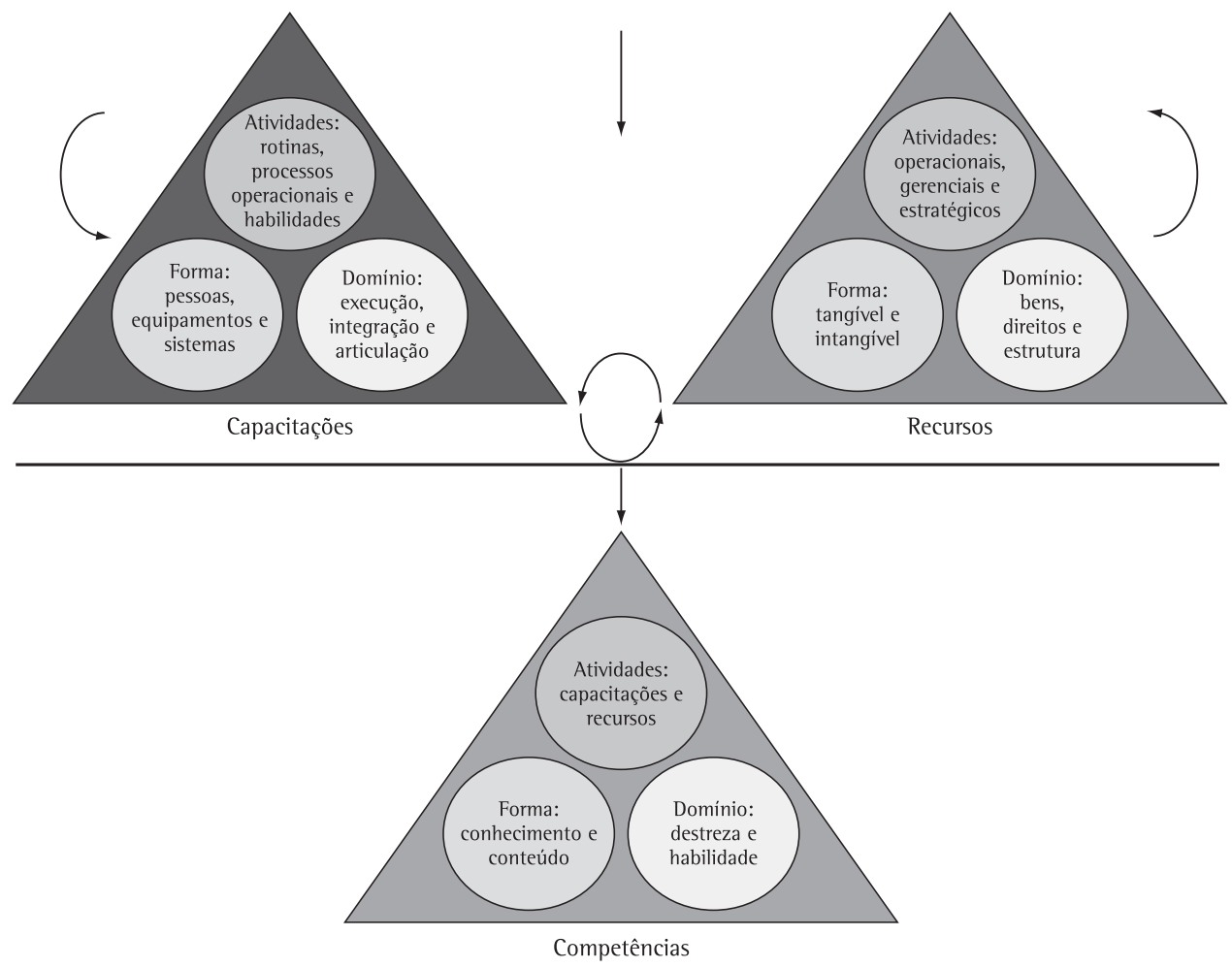

Figura 5. Tags de atributos da demonstração de resultados. Fonte: autores. 
Ressalta-se que a determinação das tags de cada atributo fundamenta-se pelo referencial teórico construído e pelos indicadores da metodologia desenvolvida por Edvinsson e Malone (1998) para a mensuração do capital intelectual.

A Figura 5 apresenta tags de atributos do agrupamento da demonstração de resultados fundamentada na Teoria Baseada em Recursos na forma de competências, capacitações e recursos.

A sistematização apresentada na Figura 5 foi estruturada em coerência com o papel exercido pelas capacitações e pelos recursos na formação das competências, bem como em concordância com as funções de cada $\operatorname{tag}$ de atributo identificado dentro da definição teórica destes conceitos.

Considerando as tags-chave de cada um dos agrupamentos, com seus respectivos atributos, é possível apresentar uma nova versão da Figura 5, desta vez com o posicionamento de cada um dos focos ou dimensões do navegador Skandia em relação aos agrupamentos da demonstração de resultados. A Figura 6 apresenta esta nova síntese.
Cada tag de atributo conferido aos agrupamentos foi sistematicamente alinhado às características, funções, definições e classificações que constam no referencial teórico.

0 posicionamento identificado para os focos do navegador Skandia também está fundamentado em atributos e tags, contribuindo estruturalmente para a integração dos atributos dos demais agrupamentos. Portanto, para o processo de desenvolvimento da identificação deste posicionamento, foram inicialmente consideradas as tags de atributos encontradas no agrupamento do capital intelectual, representadas no Quadro 10, e a partir de suas características qualitativas procurou-se então identificar a relação que estas tags, dos atributos "domínio" e "forma" dos focos do navegador Skandia, mantinham com as tags do atributo "atividades" do agrupamento das capacitações, recursos e competências (demonstração de resultados).

Com o propósito de "ilustrar" a aplicação dessa construção teórica, apresenta-se a seguir um exercício hipotético de mensuração do capital

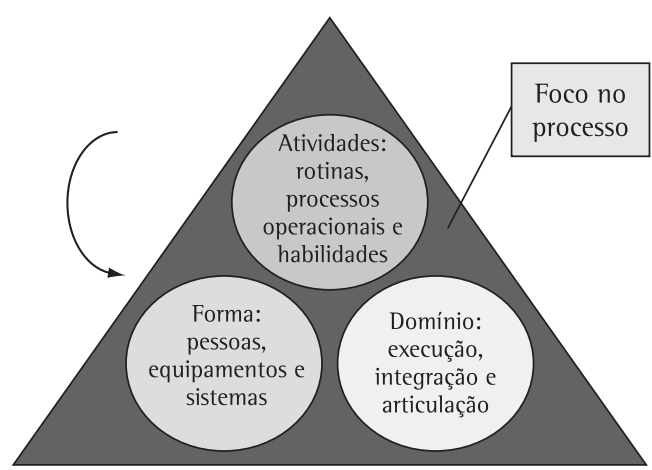

Capacitações

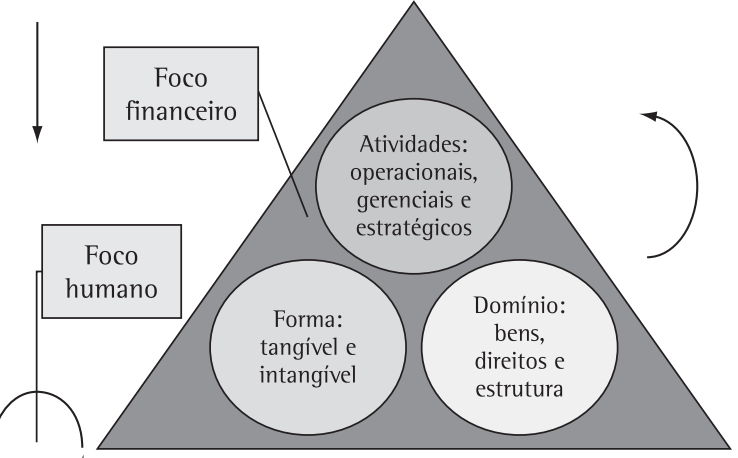

Recursos
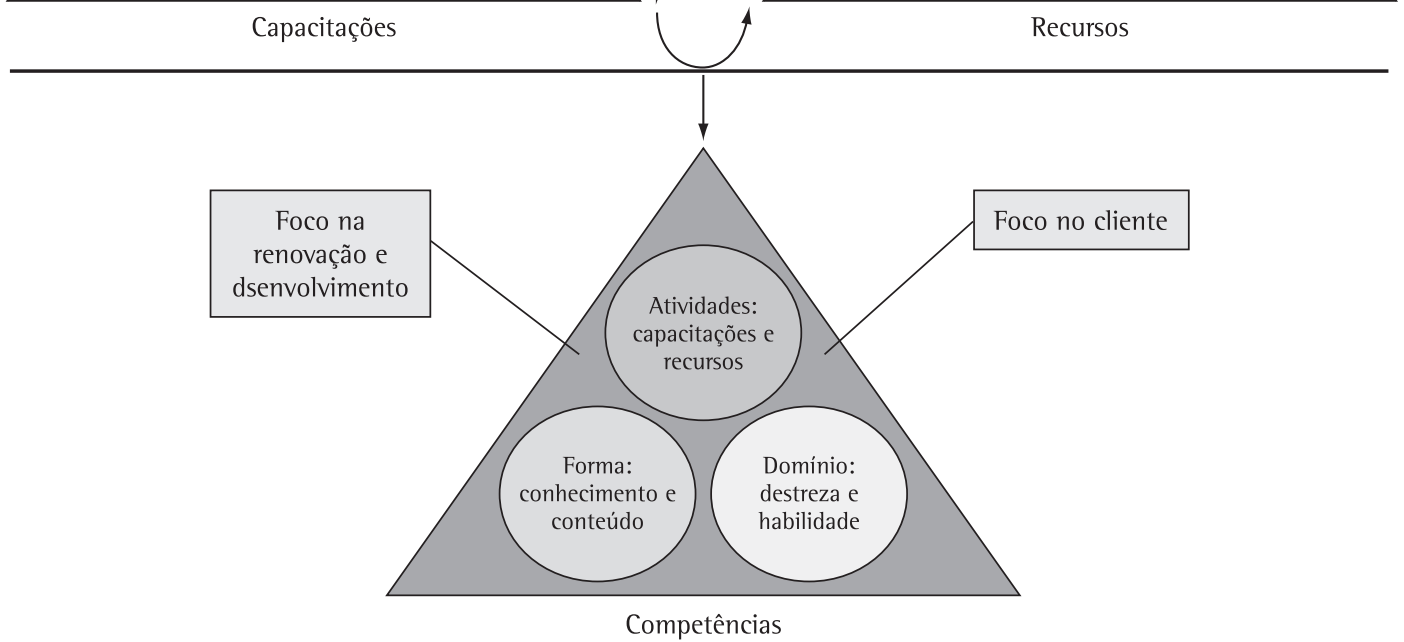

Figura 6. Tags e atributos da demonstração de resultados com o posicionamento dos focos do navegador Skandia. Fonte: autores. 
intelectual em uma empresa de serviços. Trata-se de uma aplicação parcial do modelo proposto, no entanto articulam-se todos os elementos envolvidos no processo de mensuração. São apresentados dois anos de avaliação do capital intelectual, de maneira a representar a evolução de alguns indicadores. Ao final é feita uma avaliação da variação dos indicadores. Os Quadros 11 e 12 apresentam, respectivamente, os resultados para Ano 1 e Ano 2.

Seguem-se os dados e a avaliação do capital intelectual para o Ano 2.

Para concluir a análise de mensuração do capital intelectual, faz-se a comparação entre os dois anos. São calculadas as variações do coeficiente de eficiência da utilização do $\mathrm{Cl}$ - Tabela 1, e do valor monetário do $\mathrm{Cl}$ - Tabela 2 .
Deve-se levar em conta que uma variação positiva nas duas medidas pode ser indício de forte propensão para a geração de novas competências. Se houver uma variação positiva para uma medida e negativa para a outra, pode haver propensão nula para a geração de novas competências. Finalmente, caso haja uma variação negativa nas duas medidas, pode haver forte propensão para a perda de competências.

Considerando que os indicadores i e C apresentam variações positivas do Ano 1 para 0 Ano 2, pode-se inferir que a empresa possivelmente gerou novas competências, fortalecendo, portanto, as competências apresentadas no "patrimônio líquido" da organização.

Quadro 11. Exemplo de mensuração do capital intelectual em uma empresa de serviços - Ano 1.

\begin{tabular}{|c|c|}
\hline \multicolumn{2}{|c|}{ Medida do capital intelectual em uma empresa de serviços - Ano 1} \\
\hline Ativo & Passivo \\
\hline $\begin{array}{l}\text { Capacitações } \\
\text { Foco no processo: } \\
\text { Eficiência administrativa/receitas }=95 \% \\
\text { Foco humano: } \\
\text { Índice de motivação }=85 \%\end{array}$ & $\begin{array}{l}\text { Provisão para perdas na integração das capacidades com os } \\
\text { recursos* } \\
\text { *Neste agrupamento, podem-se classificar indicadores que monitoram } \\
\text { as eventuais falhas operacionais ou os retrabalhos, os quais podem ser } \\
\text { deduzidos do total dos investimentos. }\end{array}$ \\
\hline $\begin{array}{l}\text { Recursos } \\
\text { Foco financeiro: } \\
\text { lnvestimento em Tl aplicado na } \\
\text { administração }=\$ 90.000 \\
\text { Foco humano: } \\
\text { lnvestimento no desenvolvimento da } \\
\text { competência de empregados }=\$ 10.000\end{array}$ & $\begin{array}{l}\text { Patrimônio líquido } \\
\text { Competências } \\
\text { Foco na renovação e desenvolvimento } \\
\text { Prêmio Europa pela inovação em serviços } \\
\text { Foco no cliente } \\
\text { Maior índice de renovação contratual } \\
\text { Foco financeiro } \\
\text { Taxa de rentabilidade acima da média da } \\
\text { concorrência } \\
\text { Foco no processo } \\
\text { Reconhecida pelo mercado por ter o menor } \\
\text { prazo de entrega } \\
\text { Foco humano } \\
100 \% \text { dos empregados aprovados nos } \\
\text { exames periódicos de certificação técnica }\end{array}$ \\
\hline & $\begin{array}{l}\text { Este agrupamento, seguindo a lógica da demonstração contábil, } \\
\text { representa as competências que a empresa já possui, e sofrerá ajustes } \\
\text { com a perda ou geração de competências futuras. }\end{array}$ \\
\hline \multicolumn{2}{|c|}{ Resultado da avaliação } \\
\hline \multicolumn{2}{|c|}{ Utilizando-se a equação para cálculo do capital intelectual, tem-se: } \\
\hline \multicolumn{2}{|l|}{ Bases extraídas do ativo da empresa em análise: } \\
\hline $\begin{array}{l}\text { Eficiência administrativa/receitas = 95\% } \\
\text { Índice de motivação }=85 \% \\
\text { lnvestimento em } \mathrm{Tl} \text { aplicado na administração } \\
\text { lnvestimento no desenvolvimento da competên }\end{array}$ & egados $=\$ 10.000$ \\
\hline \multicolumn{2}{|c|}{ Coeficiente de eficiência na utilização do capital intelectual (i): $(0,95+0,85) / 2=0,90$} \\
\hline \multicolumn{2}{|c|}{ Valor monetário do capital intelectual $(C):(90.000+10.000)=\$ 100.000$} \\
\hline \multicolumn{2}{|l|}{ iC: $(0,9 \times 100.000)=90.000$} \\
\hline esenta o capital int & iização no A \\
\hline
\end{tabular}

Fonte: autores. 
Quadro 12. Exemplo de mensuração do capital intelectual em uma empresa de serviços - Ano 2.

\begin{tabular}{|c|c|}
\hline \multicolumn{2}{|c|}{ Medida do capital intelectual em uma empresa de serviços - Ano 2} \\
\hline Ativo & Passivo \\
\hline $\begin{array}{l}\text { Capacitações } \\
\text { Foco no processo: } \\
\text { Eficiência administrativa/receitas = 98\% } \\
\text { Foco humano: } \\
\text { Índice de motivação }=90 \%\end{array}$ & $\begin{array}{l}\text { Provisão para perdas na integração das capacidades com os } \\
\text { recursos* } \\
\text { "Neste agrupamento, podem-se classificar indicadores que monitoram } \\
\text { as eventuais falhas operacionais ou os retrabalhos, os quais podem ser } \\
\text { deduzidos do total dos investimentos. }\end{array}$ \\
\hline Recursos & Patrimônio líquido \\
\hline $\begin{array}{l}\text { Foco financeiro: } \\
\text { lnvestimento em Tl aplicado na } \\
\text { administração = } \$ 90.000 \\
\text { Foco humano: } \\
\text { Investimento no desenvolvimento da } \\
\text { competência de empregados }=\$ 15.000\end{array}$ & $\begin{array}{l}\text { Competências } \\
\text { Foco na renovação e desenvolvimento } \\
\text { Prêmio Europa pela inovação em serviços } \\
\text { Foco no cliente } \\
\text { Maior índice de renovação contratual } \\
\text { Foco financeiro } \\
\text { Taxa de rentabilidade acima da média da } \\
\text { concorrência } \\
\text { Foco no processo } \\
\text { Reconhecida pelo mercado por ter o menor } \\
\text { prazo de entrega } \\
\text { Foco humano } \\
100 \% \text { dos empregados aprovados nos } \\
\text { exames periódicos de certificação técnica }\end{array}$ \\
\hline & $\begin{array}{l}\text { Este agrupamento, seguindo a lógica da demonstração contábil, } \\
\text { representa as competências que a empresa já possui, e sofrerá ajustes } \\
\text { com a perda ou geração de competências futuras. }\end{array}$ \\
\hline \multicolumn{2}{|c|}{ Resultado da avaliação } \\
\hline \multicolumn{2}{|c|}{ Utilizando-se a equação para cálculo do capital intelectual, tem-se: } \\
\hline \multicolumn{2}{|l|}{ Bases extraídas do ativo da empresa em análise: } \\
\hline $\begin{array}{l}\text { Eficiência administrativa/receitas }=98 \% \\
\text { Índice de motivação }=90 \% \\
\text { lnvestimento em Tl aplicado na administração } \\
\text { lnvestimento no desenvolvimento da competên }\end{array}$ & gados $=\$ 15.000$ \\
\hline \multicolumn{2}{|c|}{ Coeficiente de eficiência na utilização do capital intelectual (i): $(0,98+0,90) / 2=0,94$} \\
\hline \multicolumn{2}{|c|}{ Valor monetário do capital intelectual $(\mathrm{C}):(90.000+15.000)=\$ 105.000$} \\
\hline \multicolumn{2}{|l|}{ iC: $(0,94 \times 105.000)=98.700$} \\
\hline \multicolumn{2}{|c|}{0 resultado de $\$ 98.700$ representa o capital intelectual da organização no Ano 2.} \\
\hline
\end{tabular}

Fonte: autores.

Tabela 1. Variação do coeficiente de eficiência na utilização do capital intelectual.

\begin{tabular}{cccc}
\hline$i_{1}$ & $i_{2}$ & $\Delta i=i_{2}-i_{1}$ & $\Delta i(\%)$ \\
\hline 0,90 & 0,94 & 0,04 & $+4,44$ \\
\hline
\end{tabular}

Fonte: autores.

Tabela 2. Variação do valor monetário do capital intelectual.

\begin{tabular}{cccc}
\hline$C_{1}$ & $C_{2}$ & $\Delta C=C_{2}-C_{1}$ & $\Delta C(\%)$ \\
\hline$\$ 90.000$ & $\$ 98.700$ & $\$ 8.700$ & $+9,67$ \\
\hline
\end{tabular}

Fonte: autores.

\section{Conclusão}

0 exercício teórico desenvolvido neste artigo permitiu a compreensão da dinâmica do relacionamento dos conceitos recursos, capacitações e competências em uma perspectiva de valor associada ao capital intelectual. Também pode-se afirmar que este exercício aproximou a Teoria Baseada em Recursos dos modelos e processos desenvolvidos para a mensuração do capital intelectual, estabelecendo uma ponte entre as "operações” e a demonstração de resultados.

Nessa perspectiva, os resultados obtidos, dentro das especificidades definidas no escopo deste estudo, permitiram:

- A obtenção de um conjunto de fatores que identificam os fundamentos da Teoria Baseada em Recursos na descrição dos conceitos de competência e capacitação, por meio do um modelo de mensuração do capital intelectual;

- A explicação dos elementos constituintes dos indicadores do capital intelectual do modelo do 
navegador Skandia e sua vinculação aos conceitos de capacitação e competência através do conceito tags de atributos; e

- 0 desenvolvimento de um modelo para aplicação e integração da Teoria Baseada em Recursos na mensuração do capital intelectual.

Articulando conceitos presentes na literatura da Teoria Baseada em Recursos e nos modelos de mensuração do capital intelectual, os resultados obtidos constituem um exercício de natureza teórica. Ressaltam as dificuldades para se desenvolver estudos de natureza mais aplicada a complexidade da matéria e a própria natureza do estudo realizado. No entanto, o modelo teórico elaborado pode fundamentar a realização de estudos de caso, bem como a formulação de hipóteses em estudos de natureza mais quantitativa.

Deve-se destacar que o estudo também buscou justificar a construção de indicadores para a mobilização de recursos, possibilitando a sua transformação no desenvolvimento de novas competências organizacionais.

A aplicação prática do modelo desenvolvido para a mensuração do capital intelectual permite uma avaliação mais objetiva e pragmática da importância estratégica dos recursos organizacionais, bem como a formação de capacitações e o desenvolvimento de competências organizacionais. Valorar tais elementos constitui um importante processo para a gestão dos ativos de uma empresa, bem como fundamenta os processos de avaliação de seu valor de mercado. Este entendimento aproxima elementos definidos no nível da Gestão de Operações com a avaliação de ativos da empresa.

\section{Referências}

AMIT, R.; SHOEMAKER, P. Strategic assets and organizational rent. Strategic Management Journal, v. 14, n. 1, p. 33-46, 1993.

ANDREWS, K. R. The concept of corporate strategy. 3. ed. Homewood: R.D. Irwin, 1987.

ANSOFF, I. A nova estratégia empresarial. São Paulo: Atlas, 1990.

APOSTEL, L. Toward the formal study of models in the non-formal sciences. In: FREUDENTHAL, $\mathrm{H}$. The concept and the role of the model in mathematics and natural and socials sciences. Amsterdam: Dordtreccht, 1991. p. 1-37.

BARNEY, J. Firm resources and sustained competitive advantage Journal of Management, v. 17, n. 1, p. 99-120, 1991.

BARNEY, J. B. Gaining and sustaining competitive advantage. Reading: Addison-Wesley, 1996.

BERTO, R.; NAKANO, D. Metodologia da pesquisa e a engenharia de produção. In: ENCONTRO NACIONAL DE ENGENHARIA DE PRODUÇÃ̃0, 18., 1998, Niterói. Anais... Niterói: UFF/ABEPRO, 1998.

CHEN, Y.; WU, T. An empirical analysis of core competence for high-tech firms and traditional manufacturers. Journal of Management Development, v. 26, n. 2, p. 159-168, 2007.

CHRISTENSEN, C; OVERDORF, M. Meeting the challenge of disruptive change. Harvard Business Review, v. 78, n. 2, p. 66-76, 2000.
COHEN, W. M.; LEVINTHAL, D. A. Absorptive capacity: a new perspective on learning and innovation. Administrative Science Quaterly, v. 35, n. 1, p. 128-152, 1990.

DE TONI, A.; TONCHIA, S. New production models: a strategic view. International Journal of Production Research, v. 40, n. 18, p. 4721-4741, 2002.

DIERICKX, I; COOL, K. Asset stock accumulation and sustainability of competitive advantage. Management Science, v. 35, n. 2 , p. 1504-1511, 1989.

DOZ, Y. Managing core competency for corporate renewal: towards a managerial theory of core competencies. In: DOSI, G.; MALERBA, F. Organization strategy in the evolution of the enterprise. New York: MacMillan Press, 1996. p. 155-178.

DREJER, A.; RIIS, J. 0. Competence strategy. Copenhagen: Borsens Forlag, 2000.

DZINKOWSKI, R. The measurement and management of intellectual capital: an introduction. Management Accounting, v. 78, n. 2, p. 32-36, 2000.

EDVINSSON, L.; MALONE, M. S. Capital intelectual. São Paulo: Makron Books, 1998.

FLEURY, A.; FLEURY, M. T. L. Estratégias competitivas e competências essenciais: perspectivas para a internacionalização da indústria no Brasil. Gestão \& Produção, v. 10, n. 2, p. 129-144, 2003.

FLEURY, M. T. L.; OLIVEIRA Jr., M. M. Gestão estratégica do conhecimento: integrando aprendizagem, conhecimento e competências. São Paulo: Atlas, 2001.

FOLAN, P.; BROWNE, J. A review of performance measurement: towards performance management. Computers in Industry, v. 56, n. 7, p. 663-680, 2005.

GALBREATH, J. Which resources matter the most to firm success? An exploratory study of resource-based theory. Technovation, v. 25, n. 9, p. 979-987, 2005.

GARVIN, D. A. The processes of organization and management. Sloan Management Review, v. 39, n. 4, p. 33-50, 1998.

GRANSTRAND, 0. Intellectual capitalism: an overview. Nordic Journal of Political Economy, v. 25, n. 2, p. 115-127, 1999.

GRANT, R. M. The resource-based theory of competitive advantage: implications for strategy formulation. California Management Review, v. 33, n. 3, p. 114-135, 1991.

HAFEEZ, K.; ZHANG, Y.; MALAK, N. Determining key capabilities of a firm using analytic hierarchy process. International Journal of Production Economics, v. 76, n. 1, p. 39-51, 2002.

HAMEL, G.; PRAHALAD, C. K. Strategic intent. Harvard Business Review, v. 63, n. 4, p. 17-30, 1989.

HEIJST, G.; SPEK, R.; KRUIZINGA, E. The lessons learned Cycle. In: BORGHOFF, U. M.; PARESCHI, R. Information technology for knowledge management. Berlin: Springer-Verlag, 1998. p. 17-34.

INTERNATIONAL ACCOUNTING STANDARDS BOARD - IAS. Meeting summaries and observer notes. London, 2006. Disponivel em: <http://www.iasb.org>. Acesso em: 09 mar. 2006.

JOHANSEN, J.; RIIS, J. O. Developing a manufacturing vision. Production Planning \& Control, v. 14, n. 4, p. 327-337, 2003.

KAPLAN, R. S.; NORTON, B. A estratégia em ação: balanced scorecard. São Paulo: Campus, 1997.

LEV, B. Intangibles: management, measurement, and reporting. Washington: Brookings Press, 2001.

LEWIS, M. A. Analysing organizational competence: implications for the management of operations. International Journal of Operations and Production Management, v. 23, п. 7, p. 731-756, 2003.

LYNN, B. E. Intellectual capital: unearthing hidden value by managing intellectual assets. Ivey Business Journal, v. 65, n. 2, 2000.

MASLEN, R.; PLATTS K. W. Building manufacturing capabilities. International Journal of Manufacturing Technology and Management, v. 1, n. 4-5, p. 349-365, 2000 
MILLS, J.; PLATTS, K.; BOURNE, M. Competence and resource architectures. International Journal of Operations \& Production Management, v. 23, n. 9, p. 977-994, 2003 a.

MILLS, J.; PLATTS, K.; BOURNE, M. Applying resource-based theory: methods, outcomes and utility for managers. International Journal of Operations \& Production Management, v. 23, n. 2, p. 148-166, 2003b.

MINTZBERG, H.; AHLSTRAND, B.; LAMPEL, J. Safári de estratégia. Porto Alegre: Bookman, 2000.

MONTEALEGRE, R. A process model of capability development: lessons from the electronic commerce strategy at bolsa de valores Guayaquil. Organization Science, v. 13, n. 15, p. 514-531, 2001.

NEELY, A. D. The evolution of performance measurement research: developments in the last decade and a research agenda for the next. International Journal of Operations and Production Management, v. 25, n. 12, p. 1264-1277, 2005.

NELSON, R.; WINTER, S. An evolutionary theory of economic change. Cambridge: Harvard University Press, 1982.

PACHECO, V. Mensuração e divulgação do capital intelectual nas demonstrações contábeis: teoria e empiria. 2005. Tese (Doutorado) - Universidade Federal de Santa Catarina, Florianópolis, 2005.

PENROSE, E. The theory of the growth of the firm. London: Basil Blackwell, 1959.

PETERAF, M. A. The cornerstones of competitive advantage: a resource based view. Strategic Management Journal, v. 14, n. 3 , p. 179-191, 1993.

PFEIL, 0. P. The valuation of intellectual capital. Social Science Research Network, 2003. Working Paper Series - MIT.

PINHEIRO DE LIMA, E.; LEZANA, A. G. R. Desenvolvendo um framework para estudar a ação organizacional: das competências ao modelo organizacional. Gestão e Produção, v. 12, n. 2, p. 177-190, 2005.

PRAHALAD, J. K.; HAMEL, G. The core competence of the corporation. Harvard Business Review, v. 68, n. 6, p. 79-91, 1990.

RUMELT, R. P. Towards a strategic theory of the firm. In: LAMB, R. B. (ed.). Competitive strategic management. Englewood Cliffs: Prentice Hall, 1984.

SANCHEZ, R.; HEENE, A. A Competence perspective on strategic learning and knowledge management. In: __ (Eds.) Strategic learning and knowledge management. Chichester: John Wiley \& Sons, 1997. p. 3-15.

SOCIETY OF MANAGEMENT ACCOUNTANTS OF CANADA - SMAC (2006). Measuring knowledge assets and the management of intellectual capital: the issues and the practice. Mississauga,
2006. Disponível em: <http:// www.cma-canada.org >. Acesso em: 16 mar. 2006. (The Strategic Management Series).

STALK, G.; EVANS, P.; SHULMAN, L. E. Competing on capabilities: the new rules of corporate strategy. Harvard Business Review, v. 70, n. 2, p. 57-69, 1992.

STEWART, T. A. Capital intelectual: a nova vantagem competitiva das empresas. Rio de Janeiro: Campus, 1999.

STICKNEY, C.; WEIL, R. Contabilidade financeira: uma introdução aos conceitos, métodos e uso. São Paulo: Atlas, 2001.

SVEIBY, K. E. A Nova riqueza das organizações. Rio de Janeiro: Campus, 1998.

TEECE, D. J. Towards an economic theory of the multiproduct firm. Journal of Economic Behavior and Organization, v. 3, n. 1, p. 39-63, 1982.

TEECE, D. J.; PISANO, G.; SHUEN, A. Dynamic capabilities and strategic management. Strategic Management Journal, v. 18, n. 7, p. 509-533, 1997.

TERRA J. C.; FRAGA, R. Estimando o valor de empresas: a importância e desafios da mensuração de ativos intangiveis. 2006. Disponivel em: <http://www.terraforum.com.br/sites/ terraforum/Biblioteca>. Acesso em: 20 mar. 2006.

TIWANA, A. Knowledge management toolkit: orchestrating IT, strategy, and knowledge platforms. 2. ed. New York: Prentice-Hall, 2002.

VASCONCELOS, F. C.; CYRINO, A. B. Vantagem competitiva: os modelos teóricos atuais e a convergência entre estratégia e teoria organizacional. Revista de Administração de Empresas, v. 40 , n. 1, p. 20-37, 2000.

WERNERFELT, B. A resource-based view of the firm. Strategic Management Journal, v. 5, n. 2, p. 171-180, 1984.

WERNKE, R. Considerações acerca dos métodos de avaliação do capital intelectual. Revista Brasileira de Contabilidade, v. 31, n. 137, p. 23-39, 2002.

WHETTEN, D. A. 0 que constitui uma contribuição teórica? RAE, v. 43, n. 3, p. 69-73, 2003.

WHITWELL, G. J.; LUKAS, B. A.; HILL, P. Stock analysts' assessments of the shareholder value of intangible assets. Journal of Business Research, v. 60, n. 1, p. 84-90, 2007.

$\mathrm{WU}, \mathrm{A}$. The integration between balanced scorecard and intellectual capital. Journal of Intellectual Capital, v. 6, n. 2, p. 267-284, 2005.

YUNG-CHING, H.; TSUI-HSU, T. The impact of dynamic capabilities with market orientation and resource-based approaches on NPD project performance. Journal of American Academy of Business, v. 8, n. 1, p. 215-229, 2006.

ZARIFIAN, P. Objetivo competência: por uma nova lógica. São Paulo: Atlas, 2001.

\title{
A model for measuring intellectual capital: an approach centered on a resources-based view
}

\begin{abstract}
Understanding value creation mechanisms for producing goods and services occupies a special place in enterprises' agenda. The renaissance of Resource Based Theory is a sign of this research intensification, which is focused on organizational resources, capabilities and the role of competences in operations systems value creation. This work develops an integration model based on the intellectual capital concept, to articulate resources, capabilities and competences. The model is built using the resources, capabilities, competences and intellectual capital variables definition, addressing them in their different levels of analysis. The structure of the integration model construction used is based on the Skandia navigator model, taking into account their performance dimensions for developing this study. The result is a model that explains the integrative dynamics of resources, capabilities and competences for assessing value creation from the perspective of intellectual capital.
\end{abstract}

Keywords

Resource based theory. Intellectual capital. Organizational competences. Organizational capabilities. Performance measurement system. 